\title{
Facilitating adherence to endocrine therapy in breast cancer: stability and predictive power of treatment expectations in a 2-year prospective study
}

\author{
Yiqi Pan ${ }^{1,6}$ (Darah R. Heisig ${ }^{2} \cdot$ Pia von Blanckenburg ${ }^{3}$ - Ute-Susann Albert ${ }^{4} \cdot$ Peyman Hadji $^{5} \cdot$ Winfried Rief $^{3}$. \\ Yvonne Nestoriuc ${ }^{1,6}$
}

Received: 15 December 2017 / Accepted: 23 December 2017 / Published online: 12 January 2018

(c) The Author(s) 2018. This article is an open access publication

\begin{abstract}
Purpose To identify modifiable factors predictive of long-term adherence to adjuvant endocrine therapy (AET).

Methods As part of a 2-year cohort study in primary care $(n=116)$, we investigated whether initial treatment expectations predict adherence at 24 months after controlling for demographic, medical, and psychosocial variables. Treatment expectations were measured as necessity-concern beliefs, expected side-effect severity, and expected coping with side effects. Their stability over time and differences of trajectories between the adherent and nonadherent group were examined.

Results Nonadherence at 24 months was $14.7 \%(n=17)$. Side-effect severity at 3 months [OR $0.25,95 \% \mathrm{CI}(0.08,0.81)$, $p=0.02$ ] and necessity-concern beliefs [OR 2.03, 95\% CI $(1.11,3.72), p=0.02$ ] were the sole predictors of adherence. Necessity-concern beliefs remained stable over 2 years, whereas expected side-effect severity $\left(p=0.01, \eta_{\mathrm{p}}^{2}=0.07\right)$ and expected coping with side effects became less optimistic over time $\left(p<0.001, \eta_{\mathrm{p}}^{2}=0.19\right)$, the latter particularly among nonadherers $\left(p<0.01, \eta_{\mathrm{p}}^{2}=0.10\right)$.

Conclusions Patients' initial necessity-concern beliefs about the AET and early severity of side effects affect long-term adherence. Expecting poor management of side effects may also facilitate nonadherence. We suggest that discussing benefits, addressing concerns of AET, and providing side-effect coping strategies could constitute a feasible and promising option to improve adherence in clinical practice.
\end{abstract}

Keywords Adherence $\cdot$ Expectation $\cdot$ Endocrine therapy $\cdot$ Adverse events $\cdot$ Breast cancer

Electronic supplementary material The online version of this article (https://doi.org/10.1007/s10549-017-4637-2) contains supplementary material, which is available to authorized users.

Yiqi Pan

y.pan@uke.de

1 Department of Psychosomatic Medicine and Psychotherapy, University Medical Center Hamburg-Eppendorf, Martinistraße 52, 20251 Hamburg, Germany

2 Clinical Psychology and Psychotherapy, University of Hamburg, Von-Melle-Park 5, 20146 Hamburg, Germany

3 Department of Clinical Psychology and Psychotherapy, Philipps-University of Marburg, Gutenbergstraße 18, 35032 Marburg, Germany

\section{Introduction}

Nonadherence rates in adjuvant endocrine therapy (AET) for breast cancer range from 41 to $72 \%$ at 5 years [36] including $30-47 \%$ patients who have discontinued $[5,25]$. Nonadherence lead to a higher risk of all-cause mortality and recurrence compared to completion of treatment $[16,33]$.

4 AWMF-Institute for Medical Knowledge Management, Philipps-University of Marburg, Karl-von-Frisch-Str. 1, 35043 Marburg, Germany

5 Department of Gynecology and Obstetrics, Krankenhaus Nordwest, Steinbacher Hohl 2-26, 60488 Frankfurt am Main, Germany

6 Schön Klinik Hamburg Eilbek, University Clinic for Psychosomatic Medicine and Psychotherapy, Dehnhaide 120, 20081 Hamburg, Germany 
Currently, three treatments are available: Tamoxifen, Aromatase Inhibitors, and Fulvestrant (used in the metastatic setting). With breast cancer being the most common cancer for women worldwide [27] and AET assigned for approximately $75 \%$ of all breast cancer cases [37], it is important to understand which factors are related to nonadherence. Meta-analyses and systematic reviews have reported that the most consistent demographic, clinical and treatment characteristics related to nonadherence in AET are younger age, follow-up care by a general practitioner versus an oncologist or gynecologist, increased costs, medication switch, higher frequency of hospitalizations, and treatment side effects [9, $34,36]$.

Side effects include vasomotor symptoms, arthralgia, nausea, weight gain, vaginal dryness, and many others. Incidence rates of $21-43 \%$ were found for hot flushes and arthralgia in clinical trials $[11,15,43]$ and indicate that side effects are common, can be burdensome, and for some, to such a degree that quality-of-life is largely affected [11]. However, as noted by Cahir et al. [9], it remains unknown whether it is the side effects per se or poor side-effect coping that leads to nonadherence. Aside from pharmacodynamics of the drug, side effects can be influenced by one's expectations of side effects occurrence and intensity, a phenomenon known as the 'nocebo-effect' [14]. Studies with breast cancer patients undergoing chemotherapy or AET have found that expecting more side effects can lead to more actual side effects $[12,38,41]$. Given the relations between nonadherence and side effects, and side-effect and side-effect expectations, investigating the immediate relationship between side-effect expectations and adherence is warranted.

One expectation factor which has been frequently researched with regard to adherence is the patient's perceived treatment necessity (e.g., to prevent recurrence) and related concerns (e.g., side effects, potential drug dependency). The underlying theoretical framework suggests that patients individually weigh their perceived necessity against their concerns and derive corresponding behavior [23]. Accordingly, if concerns outweigh necessity, nonadherent behavior would be more probable. The link between necessity-concern beliefs and adherence to AET has been found in a small body of studies [8, 18, 19, 28, 30, 42], including two longitudinal studies with a follow-up of 2 and 5 years $[18,30]$. However, a recent review argues that the overall evidence remains tentative since most studies were crosssectional [34] and some studies used unvalidated measures of necessity-concern beliefs [8, 18, 30, 42].

The goal of this study was to examine stability and predictive power of initial treatment expectations, i.e., expected side-effect severity, expected coping with side effects, and necessity-concern beliefs on adherence to AET after 24 months in a multivariate model along with clinical, demographic, and psychosocial characteristics. Also, up to now, it remains unknown whether treatment expectations change or remain stable over the course of the treatment. Furthering our understanding of modifiable factors like expectations could be helpful to design interventions with the objective to increase adherent behavior.

\section{Methods}

\section{Patients and procedure}

This sample was based off a clinical cohort study. Patients $(n=116)$ were women with hormone receptor-positive breast cancer or DCIS indicated for AET. Other adjuvant therapies were not an exclusion criterion. The recruitment process, further inclusion criteria, and study flow were described in detail elsewhere [38]. Informed consent was given by all patients before study inclusion. We standardized the amount of pre-knowledge about the AET as much as possible by providing all participants with prior validated information about beneficial effects and side effects of the treatment (verbally and using a leaflet) [22]. The ethics committee for medical research of the University of Marburg and the ethics committee of the medical chamber of Hamburg gave ethical approval.

\section{Measures}

Except for necessity-concern beliefs and side effects, which were assessed at 3 months, all enlisted variables were collected around treatment start. For 21 patients, these variables were collected after they had started AET ( $M=7$ days, range 1-31 days). Treatment expectations and adherence were additionally assessed at 24 months. When patients had already discontinued AET at assessment time, they were instructed to refer to the time period shortly before discontinuation.

\section{Demographic and medical characteristics}

A semistructured interview and the clinical assessment in neuropsychiatry (SCAN) [51] were used to assess demographics, comorbidities, and concurrent medication. Disease information was collected from medical records. The generic assessment of side effects (GASE) [39] measured physical symptoms at treatment start (baseline symptoms) and side effects at 3-month follow-up. The questionnaire listed 45 symptoms including 36 of the most common adverse effects across different medications and 9 of which were specific of the AET [38]. A global question on severity and burden concluded the symptom listing ("Please indicate how much you have overall suffered from these symptoms in the last 7 days"). All symptoms including the global item were rated 
on a scale from 0 (none) to 3 (severe). We used the global scale due to its easier interpretation. In addition, we calculated the number of side effects and a mean severity score by averaging the severity of 44 symptoms (menstrual symptoms excluded since $80 \%$ of our sample was postmenopausal).

\section{Psychosocial characteristics}

The hospital anxiety and depression scale (HADS) [53] measured anxiety and depression, calculated as the sum of all items [6]. Quality-of-life was assessed by the global quality-of-life scale of the questionnaire of the European organization for research and treatment of cancer (EORTC QLQ-C30) ("how would you rate your overall quality of life during the last week?") [1].

\section{Treatment expectations}

The beliefs about medicines questionnaire (BMQ) [24] assessed necessity-concern beliefs about the AET. Cronbach's Alpha ranged from $\alpha=0.76$ to $\alpha=0.77$ (necessity subscale) and from $\alpha=0.66$ to $\alpha=0.74$ (concern subscale). Necessity-concern beliefs had a range from -4 to 4 and were obtained by subtracting "concern" from "necessity." Expected side-effect severity and expected coping with side effects were assessed using the GASE-Expect [38, 39]. Patients indicated expected severity and burden of future side effects $(0=$ none expected to $3=$ severe $)$ and how well they would be able to cope with them $(0=$ poorly to $3=w e l l)$.

\section{Adherence}

Adherence was assessed via self-report with a validated single item ("how many pills have you actually taken during the last week?") [54]. Patients who discontinued treatment were additionally requested to specify the reason (open question). We used an $80 \%$ criterion to categorize adherers and nonadherers. This criterion is commonly applied for adherence to AET $[4,50]$ and has proven critical with respect to mortality reduction [32]. Due to our overall small sample size, we did not conduct analyses for adherence and persistence separately.

\section{Data analyses}

Missing values analysis was imputed using multiple imputation algorithms [40]. Entire missing questionnaires were not imputed.

We included $n=116$ patients in the adherence analyses. A hierarchical logistic regression was conducted with demographic and medical variables, baseline symptom severity, and side-effect severity, being entered in the first step. Anxiety and depression and quality-of-life were entered in the second step, followed by necessity-concern beliefs, expected side-effect severity, and expected coping with side effects in the third step. Three patients dropped out of the study at 3 months and had already discontinued treatment at that time. Since the majority of patients do not resume therapy after discontinuation [5], we included these patients as nonadherers. However, the possibility that treatment was resumed could not be excluded. Hence, we conducted a sensitivity analysis under exclusion of these three patients. Further sensitivity analyses were performed by substituting the global side-effect severity scale by the mean severity score, and numbers of side effects in the regression analysis, respectively.

Stability analysis included further data at 24 months and was conducted with $n=102$ participants. A $2 \times 2$ mixed analyses of variance (ANOVAs) was conducted with adherence status at 24 months as the between-subjects factor (adherent vs. nonadherent) and time as the withinsubject factor (treatment start vs. 24-month follow-up).

\section{Results}

\section{Patient characteristics}

Table 1 shows the sample characteristics at treatment start. The mean age was $M=55.40$ years $(\mathrm{SD}=9.97)$. Most women had a partner $(74 \%)$, reported primary or secondary education (82\%), were diagnosed with breast cancer stage I (52\%) and had at least one medical comorbidity (70\%). The average number of prescription medications besides AET was $M=1.5(\mathrm{SD}=1.50)$. After 3 months of AET, $84 \%$ of patients reported side effects of mild (43\%) or moderate (36\%) intensity. Quality-of-life was rated as good $(M=4.91, \mathrm{SD}=1.41)$ and anxiety and depression as rather low $(M=8.24, \mathrm{SD}=6.13)$. Necessity-concern beliefs were close to zero, indicating that on average, patients reported concerns equaled the perceived necessity of the treatment $(M=0.38, \mathrm{SD}=1.11)$. Expected side-effect severity $(M=1.21, \mathrm{SD}=0.61)$ was rated as mild and expected coping with side effects $(M=1.91$, $\mathrm{SD}=0.60)$ was rated as rather well. The adherence rate was $85 \%$ at 24 months. Of the 17 patients $(15 \%)$ who were classified as nonadherers, four women discontinued AET within the first three months, whereas 11 patients discontinued between months 3 and 24. Two had taken less than $80 \%$ of the pills at 24-month follow-up. The exact time of discontinuation was known for $n=7$ patients. On average, these patients discontinued after 17 months (range 10-24 months). 
Table 1 Patients'

sociodemographic and clinical characteristics $(N=116)$

\begin{tabular}{|c|c|}
\hline Characteristic & $n(\%)$ or mean $(\mathrm{SD})$, range \\
\hline Age, years & $55.40(9.97,26-79)$ \\
\hline Married/partner & $86(74.1 \%)$ \\
\hline$<13$ years of education & $95(81.9 \%)$ \\
\hline \multicolumn{2}{|l|}{ Tumor staging UICC } \\
\hline 0 & $4(3.4 \%)$ \\
\hline I & $60(51.7 \%)$ \\
\hline II & $36(31.0 \%)$ \\
\hline III & $12(10.3 \%)$ \\
\hline IV & $4(3.4 \%)$ \\
\hline \multicolumn{2}{|l|}{ Comorbid health condition } \\
\hline None & $35(30.2 \%)$ \\
\hline At least one & $81(69.8 \%)$ \\
\hline \multicolumn{2}{|l|}{ Number of concurrent medications } \\
\hline 0 & $39(33.6 \%)$ \\
\hline 1 & $29(25.0 \%)$ \\
\hline 2 & $20(17.2 \%)$ \\
\hline 3 & $16(13.8 \%)$ \\
\hline 4 & $4(3.4 \%)$ \\
\hline 5 or more & $8(6.9 \%)$ \\
\hline \multicolumn{2}{|l|}{ Baseline symptom severity } \\
\hline No symptoms & $19(16.4 \%)$ \\
\hline Mild symptoms & $71(61.2 \%)$ \\
\hline Moderate symptoms & $26(22.4 \%)$ \\
\hline \multicolumn{2}{|l|}{ Type of AET medication } \\
\hline Tamoxifen & $50(43.1 \%)$ \\
\hline Aromatase Inhibitor & $66(56.9 \%)$ \\
\hline Medication switch within the first 3 months & $7(6.0 \%)$ \\
\hline \multicolumn{2}{|l|}{ Side-effect severity at 3 months } \\
\hline No side effects & $18(15.5 \%)$ \\
\hline Mild side effects & $50(43.1 \%)$ \\
\hline Moderate side effects & $42(36.2 \%)$ \\
\hline Severe side effects & $6(5.2 \%)$ \\
\hline Quality-of-life (scale range: $0-7$ ) & $4.91(1.41)$ \\
\hline Anxiety and depression (scale range: $0-21$ ) & $8.24(6.13)$ \\
\hline Necessity-concern beliefs (scale range: $-4-4)^{\mathrm{a}}$ & $0.38(1.11)$ \\
\hline Expected side-effect severity (scale range: $0-3$ ) & $1.21(0.61)$ \\
\hline Expected coping with side effects (scale range: $0-3$ ) & $1.91(0.60)$ \\
\hline \multicolumn{2}{|l|}{ Adherence at 24 months } \\
\hline Adherent ( $\geq 80 \%$ intake) & $99(85.3 \%)$ \\
\hline Nonadherent $(<80 \%$ or discontinuation) & $17(14.7 \%)$ \\
\hline Discontinuation at 3 months & $4(3.4 \%)$ \\
\hline Discontinuation between 3 and 24 months & $11(9.5 \%)$ \\
\hline$<80 \%$ at $24-$ month FU & $2(1.7 \%)$ \\
\hline
\end{tabular}

UICC union for international cancer control, $A E T$ adjuvant endocrine therapy, $F U$ follow-up

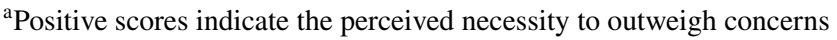

\section{Prediction of adherence}

Variables bivariately associated with adherence were lower side-effect severity at 3 months $(r=-0.33, p<0.001)$, lower anxiety and depression $(r=-0.18, p=0.049)$, higher necessity-concern beliefs $(r=0.28, p=0.002)$, and lower expected side-effect severity $(r=-0.22, p=0.02)$ (supplement 1). 
Table 2 Multiple logistic regression model for predictors of 24-month adherence to AET

\begin{tabular}{|c|c|c|c|c|c|c|}
\hline \multirow[t]{2}{*}{ Predictors } & \multicolumn{2}{|l|}{ Model 1} & \multicolumn{2}{|l|}{ Model 2} & \multicolumn{2}{|l|}{ Model 3} \\
\hline & OR $[95 \% \mathrm{CI}]$ & $p$ & OR $[95 \% \mathrm{CI}]$ & $p$ & OR $[95 \% \mathrm{CI}]$ & $p$ \\
\hline Age & $1.03[0.95-1.11]$ & 0.45 & $1.02[0.94-1.11]$ & 0.61 & $1.04[0.95-1.14]$ & 0.38 \\
\hline \multicolumn{7}{|l|}{ Marital status } \\
\hline \multicolumn{7}{|l|}{ Single $=0$} \\
\hline Married/partner $=1$ & $0.89[0.24-3.31]$ & 0.86 & $0.98[0.25-3.86]$ & 0.98 & $0.75[0.17-3.36]$ & 0.70 \\
\hline \multicolumn{7}{|l|}{ Education } \\
\hline \multicolumn{7}{|l|}{$\leq 13$ years $=0$} \\
\hline$>13$ years $=1$ & $1.46[0.29-7.46]$ & 0.65 & $1.60[0.30-8.63]$ & 0.59 & $1.95[0.31-12.41]$ & 0.48 \\
\hline Staging & $1.28[0.63-2.62]$ & 0.50 & $1.32[0.64-2.73]$ & 0.45 & $1.17[0.53-2.54]$ & 0.70 \\
\hline \multicolumn{7}{|l|}{ Physical comorbidity } \\
\hline \multicolumn{7}{|l|}{ None $=0$} \\
\hline At least one $=1$ & $1.00[0.15-6.83]$ & 0.99 & $1.03[0.15-7.22]$ & 0.98 & $0.84[0.11-6.62]$ & 0.87 \\
\hline Number of concurrent medications & $0.73[0.44-1.20]$ & 0.21 & $0.75[0.45-1.25]$ & 0.26 & $0.59[0.33-1.08]$ & 0.09 \\
\hline Baseline symptom severity & $1.39[0.44-4.36]$ & 0.58 & $1.50[0.45-4.99]$ & 0.51 & $1.89[0.45-7.87]$ & 0.38 \\
\hline \multicolumn{7}{|l|}{ Type of AET } \\
\hline \multicolumn{7}{|l|}{ Tamoxifen $=0$} \\
\hline Aromatase inhibitor $=1$ & $2.63[0.67-10.30]$ & 0.17 & $2.58[0.66-10.18]$ & 0.18 & $2.40[0.55-10.80]$ & 0.24 \\
\hline \multicolumn{7}{|l|}{ Medication switch } \\
\hline \multicolumn{7}{|l|}{ No switch $=0$} \\
\hline Switch within first $3 \mathrm{M}=1$ & $0.29[0.01-6.52]$ & 0.44 & $0.40[0.02-9.27]$ & 0.57 & $0.49[0.004-13.51]$ & 0.49 \\
\hline Side-effect severity at $3 \mathrm{M}$ & $\mathbf{0 . 2 2}[0.08-0.62]$ & $0.004 * *$ & $\mathbf{0 . 2 2}[0.08-0.64]$ & $0.005 * *$ & $\mathbf{0 . 2 5}[0.08-0.81]$ & $0.02 *$ \\
\hline Quality-of-life & & & $0.89[0.52-1.52]$ & 0.68 & $0.84[0.47-1.51]$ & 0.56 \\
\hline Anxiety and depression & & & $0.95[0.85-1.08]$ & 0.43 & $0.95[0.83-1.08]$ & 0.41 \\
\hline Necessity-concern beliefs & & & & & $\mathbf{2 . 0 3}[1.11-3.72]$ & $0.02 *$ \\
\hline Expected side-effect severity & & & & & $0.72[0.19-2.82]$ & 0.64 \\
\hline Expected coping with side effects & & & & & $0.94[0.23-3.75]$ & 0.93 \\
\hline \multicolumn{7}{|l|}{ Model fit indices and significant tests } \\
\hline \multirow[t]{2}{*}{ Nagelkerke's $\Delta R^{2}$} & 0.26 & & 0.01 & & 0.09 & \\
\hline & $\chi^{2}(10)=18.22, p=0.05$ & & $\chi^{2}(2)=0.64, p=0.73$ & & $\chi^{2}(3)=7.40, p=0.06$ & \\
\hline \multirow[t]{2}{*}{ Total Nagelkerke's $R^{2}$} & & & 0.27 & & 0.36 & \\
\hline & & & $\chi^{2}(12)=18.87, p=0.09$ & & $\chi^{2}(15)=26.27, p=0.04^{*}$ & \\
\hline
\end{tabular}

Note $N=116$. Tests which obtained significance are in boldface

$O R$ odds ratio, $C I$ confidence interval, $A E T$ adjuvant endocrine therapy, $M=$ months

$* p<0.05, * * p<0.01$

In the regression model, adherence was predicted by sideeffect severity at 3 months [OR $0.25,95 \%$ CI $(0.08,0.81)$, $p=0.02$ ], and necessity-concern beliefs [OR $2.03,95 \%$ CI $(1.11,3.72), p=0.02]$ (Table 2). The model explained $36 \%$ of the variance in adherence (Nagelkerke's $R^{2}$ ) and obtained significance $\left(\chi^{2}(15)=26.27, p=0.04\right)$. Adherence status was predicted correctly in $87.9 \%$ of the cases. Sensitivity analyses without the three patients who were nonadherent at 3 months and lost to follow-up subsequently showed the same results.

We repeated the analysis and substituted the global items of baseline symptom severity and side-effect severity by the respective mean intensity score of the 44 listed symptoms. We obtained the same result pattern with significant multivariate associations between adherence and side-effect severity [OR $0.53,95 \%$ CI $(0.003,0.91)$, $p=0.04$ ], and necessity-concern beliefs [OR 2.42, 95\% CI $(1.19,4.92), p=0.02$; Model: Nagelkerke's $R^{2}=41 \%$; $\left.\chi^{2}(15)=30.66, p=0.01\right]$. Interestingly, when number of side effects (controlled for number of baseline symptoms) was entered instead of side-effect severity, its link to adherence was not present anymore [OR $0.90,95 \% \mathrm{CI}$ $(0.79,1.02), p=0.09]$. Necessity-concern beliefs, however, remained predictive of adherence [OR $2.14,95 \% \mathrm{CI}$ $(1.13,4.06), p=0.02]$. 
Table 3 Treatment expectations at treatment start and at 24-month follow-up ( $M$ [SD])

\begin{tabular}{|c|c|c|c|c|c|c|c|c|c|}
\hline & \multicolumn{3}{|c|}{ Total sample } & \multicolumn{3}{|l|}{ Adherent } & \multicolumn{3}{|l|}{ Nonadherent } \\
\hline & $\begin{array}{l}\text { Treat- } \\
\text { ment start } \\
(n=116)\end{array}$ & $\begin{array}{l}24 \text { months } \\
(n=102)\end{array}$ & Correlation & $\begin{array}{l}\text { Treat- } \\
\text { ment start } \\
(n=99)\end{array}$ & $\begin{array}{l}24 \text { months } \\
(n=96)\end{array}$ & Correlation & $\begin{array}{l}\text { Treatment } \\
\text { start }(n=17)\end{array}$ & $\begin{array}{l}24 \text { months } \\
(n=8)^{\mathrm{a}}\end{array}$ & Correlation \\
\hline $\begin{array}{l}\text { Necessity- } \\
\text { concern } \\
\text { beliefs }\end{array}$ & $0.38(1.11)$ & $0.33(1.03)$ & $0.52 * *$ & $0.51(0.88)$ & $0.44(0.94)$ & $0.38 * *$ & $-0.38(1.84)$ & $-1.07(1.22)$ & $\mathbf{0 . 8 5} *$ \\
\hline $\begin{array}{l}\text { Expected } \\
\text { side-effect } \\
\text { severity }\end{array}$ & $1.21(0.61)$ & $1.39(0.78)$ & $0.24 *$ & $1.15(0.58)$ & $1.31(0.75)$ & 0.16 & $1.53(0.72)$ & $2.13(0.84)$ & 0.57 \\
\hline $\begin{array}{l}\text { Expected } \\
\text { coping with } \\
\text { side effects }\end{array}$ & $1.91(0.60)$ & $1.66(0.77)$ & $0.34 * *$ & $1.94(0.53)$ & $1.74(0.70)$ & $0.36 * *$ & $1.71(0.92)$ & $0.63(0.74)$ & 0.27 \\
\hline
\end{tabular}

The necessity-concern beliefs scale ranges from -4 to 4 . Higher values indicate the perceived necessity to outweigh concerns. The scales for expected side-effect severity and expected coping with side effects range from 0 to 3 . Significant correlations are in boldface. Data at 24 months was available for $n=102$ patients due to lost to follow-up

$M$ mean, $S D$ standard deviation, Start treatment start, $F U$ 24-month follow-up

$* p<0.05, * * p<0.01$

${ }^{a}$ Of $n=8$ nonadherent patients who specified treatment expectations, 6 discontinued treatment, 2 took less than $80 \%$ of the pills

\section{Stability of treatment expectations}

We then compared treatment expectations at treatment start and at 24-month follow-up. Table 3 shows means, standard deviations and correlations by adherence status of both time points.

Results of the mixed ANOVA showed no main effect of time for necessity-concern beliefs $[F(1,100)=0.004$, $\left.p=0.95, \eta_{p}^{2}<0.001\right]$, indicating that it did not change over time. However, side effects were expected to become more severe $\left[F(1,98)=6.78, p=0.01, \eta_{p}^{2}=0.07\right]$, and expected coping with side effects was rated as more poorly over the course of 2 years $\left[F(1,99)=22.57, p<0.001, \eta_{p}^{2}=0.19\right]$. Significant between-subject effects indicate that adherent and nonadherent patients overall differed in their treatment expectations $\left[F_{\text {Necessity-concern beliefs }}(1,100)=24.77\right.$, $p<0.001, \eta_{p}^{2}=0.20 ; F_{\text {expected side effect severity }}(1,98)=9.40$, $p=0.003, \eta_{p}^{2}=0.09 ; F$ expected coping with side effects $(1$, $\left.99)=11.42, p=0.001, \eta_{p}^{2}=0.10\right]$. A significant interaction effect for Adherence $\times$ Time was found for expected coping with side effects $\left[F(1,99)=11.42, p<0.01, \eta_{p}^{2}=0.10\right]$, yet neither for necessity-concern beliefs $[F(1,100)=0.10$, $\left.p=0.75, \eta_{p}^{2}=0.001\right]$, nor for expected side-effect severity $\left[F(1,98)=2.00, p=0.16, \eta_{p}^{2}=0.02\right]$. We computed the change over time of each expectation variable relative to their scale range. As shown in Fig. 1, necessity-concern beliefs remained stable, whereas expected coping with side effects became less optimistic by 5.4 and $37.5 \%$ among adherent and nonadherent patients. Expected side-effect severity trajectories increased by 6.1 and $20.83 \%$. However, this difference in trajectory was not significant. Additional analysis on the stability of side-effect severity showed no significant effects, neither for Time $[F(1,100)=0.48$, $\left.p=0.49, \eta_{p}^{2}=0.01\right]$, nor for the Adherence $\times$ Time interaction $\left[F(1,100)=0.58, p=0.45, \eta_{p}^{2}=0.01\right]$.

\section{Reasons for discontinuation}

The reasons for discontinuation are depicted in Fig. 2. Five patients indicated to have discontinued due to side effects. One and three patients indicated to have discontinued due to worries about potential serious adverse side effects of the AET and actual serious adverse events (metastasis; liver cancer), respectively. Another 6 patients reported to have discontinued yet were unattainable for further inquiries.

\section{Discussion}

In a prospective cohort study in primary care with 116 patients, we documented a nonadherence rate of $14.7 \%$ after 2 years. Initial side-effect severity and necessity-concern beliefs predicted long-term adherence over and above the influence of sociodemographic, other medical, and psychosocial characteristics. Expected side-effect severity and expected coping with side effects did not predict adherence. Necessity-concern beliefs remained stable on an overall medium level over the course of 2 years, whereas side-effect and coping expectations became less optimistic over time. The trajectories of coping expectations differed by adherence status at 24 months with expected coping being less optimistic among the nonadherent than the adherent patients.

Our findings indicate that, given a scale range from -4 to 4 , a patient with a necessity-concern beliefs value of 1 (i.e., 

ment expectations over 2 years as a function of 24 months adherence status to adjuvant endocrine therapy. Percentages are relative to the respective scale range. A significant Time $\times$ Adherence interaction effect was found for expected coping with side effects $(p<0.01)$
Fig. 1 Change of patients' treat-

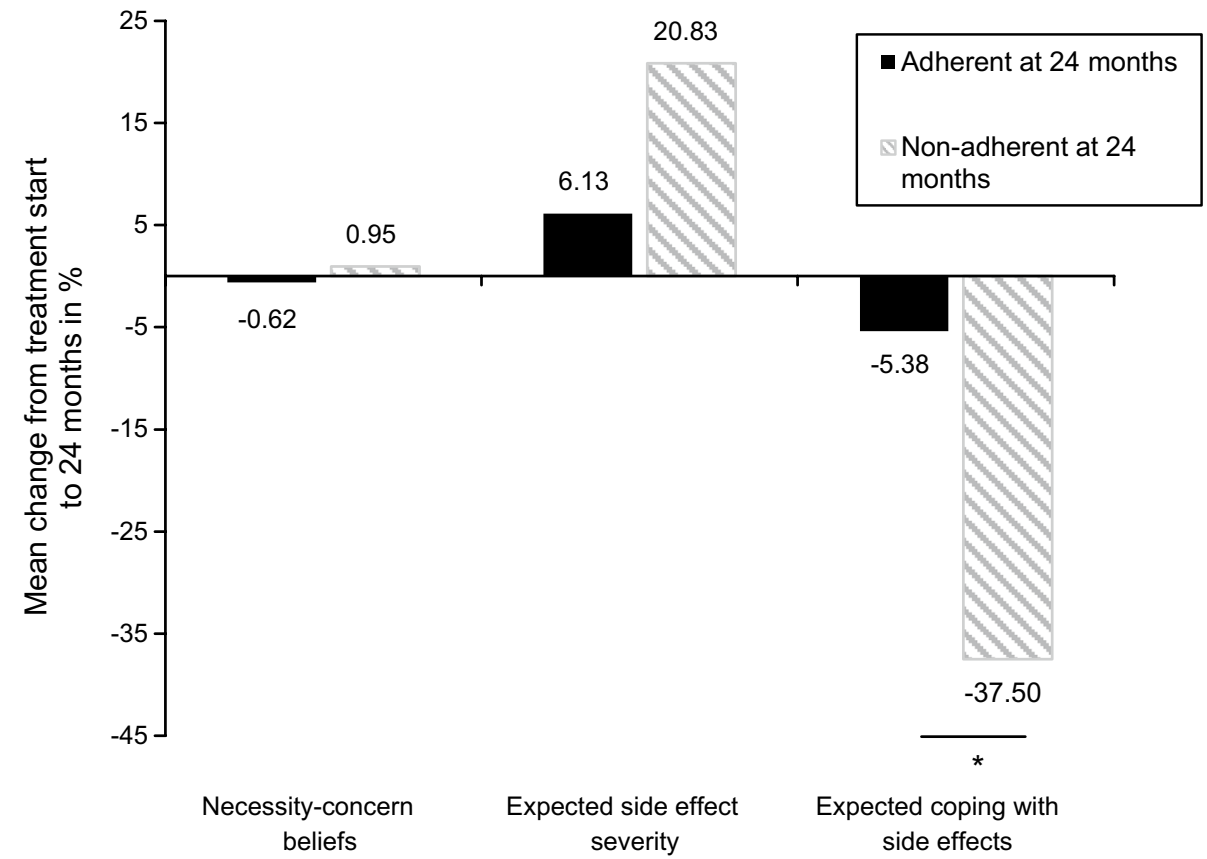

Fig. 2 Patient-reported reasons for discontinuing adjuvant endocrine treatment

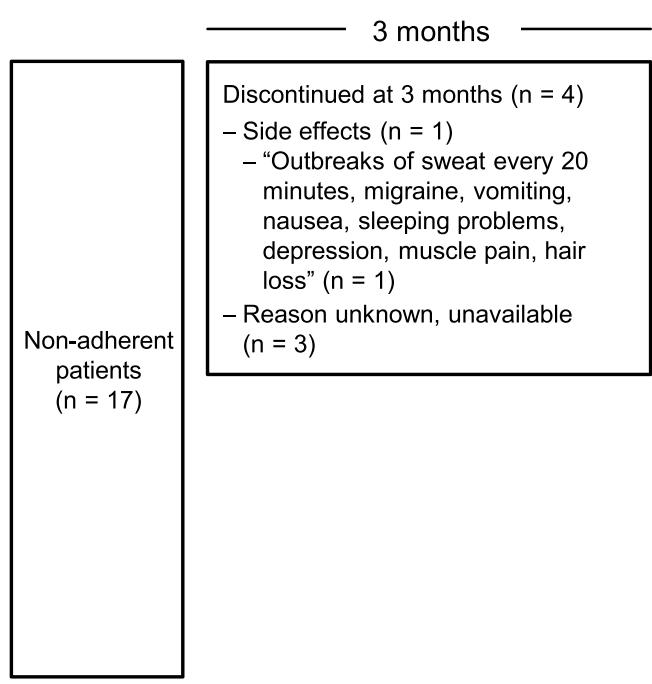

necessity slighter higher than concerns) is two times more likely to be adherent than a patient with necessity-concern beliefs of 0 (i.e., necessity and concerns equally high). A patient with necessity-concern beliefs of 2, again, is four times more likely to be adherent. As for side effects, a patient with mild side effects is four times more likely to be adherent than a patient with moderate side effects. Our finding adds to the line of studies which linked necessity-concern beliefs to AET adherence [2, 8, 18, 19, 28, 30, 42, 46, 52]. Hereby, our study is the first to report this relationship in a prospective design over 24 months using a validated questionnaire of necessity-concern beliefs. These results also indicate that side-effect severity and necessity-concern beliefs play a pivotal role in AET adherence over and above demographic and clinical characteristics, which did not contribute to the prediction. Except for younger age, the latter finding aligns with reviews and meta-analyses which reported inconsistent associations between adherence and most demographic and clinical characteristics [9, 34, 36], including qualityof-life [45], depression [31], and medication switch, which facilitated adherence in some studies, and nonadherence in others [34].

The influence of side effects on adherence was also implied by patients' self-reports, given that five out of 15 patients named "side effects" as their reason for discontinuation. Notably, whereas side-effect severity predicted adherence in the logistic regression model, numbers of side effects did not, suggesting that the link may differ depending 
on how side effects are operationalized. This has also been reflected by reviews $[9,34]$, which reported the relationship between side effects and adherence to be inconsistent across studies. We propose that the link is unequivocal since it might be influenced by side-effect appraisal. For example, a recent qualitative study found that women were more willing to accept side effects when they were aware that the treatment was necessary to prevent recurrence [35]. Moreover, our findings indicated that side-effect management may play a role considering adherence, giving that, especially among the nonadherent group, expected coping with side effects became less optimistic over time (37.5\% vs. $5.4 \%$ for nonadherent and adherent patients). As side-effect severity did not change significantly from 3 to 24 months-neither in the overall sample nor in the nonadherent or adherent patient group - these results suggest that expected low selfefficacy to cope with future side effects may influence adherence behavior which goes beyond side effects per se. Taken together, we suggest that burden of side effects may affect adherence behavior, yet should be examined in the context of further related factors, e.g., necessity-concern beliefs and side-effect management.

In the literature, side-effect management is acknowledged as important to maintain or increase adherence to AET [21, 48], and a variety of recommendations are suggested for different side-effect categories [17]. However, systematic research examining the degree of its implementation is lacking, whereas trials which investigate the efficacy of those strategies are few (e.g. for hot flushes, see [44] for arthralgia, see $[3,13])$. Although due to the correlative nature of the data, we cannot answer the question whether patients discontinue treatment because they expect their management to be ineffective or whether they discontinue first and rationalize their behavior thereafter, our findings nonetheless reinforce the importance of side-effect coping in AET. Its pivotal role considering adherence optimization has also been pointed out by both patients $[46,48]$ and practitioners [49] in prior qualitative studies. Furthermore, in a trial of cognitive-behavioral therapy for vasomotor symptoms of breast cancer survivors, beliefs about coping and control of hot flushes were found to be the main mediator of how burdensome symptoms were perceived after the therapy [10]. Overall, more studies are needed to investigate whether poor coping abilities lead to nonadherence, and to which degree patients wish for further support.

Limitations of this study include a selection bias. The enhanced information about AET which was provided as part of the study might have appealed to women who were more open to the treatment or perhaps even increased patients' willingness to be adherent. We believe the latter bias to be minor since interventions which aimed at improving adherence by providing information were found to be not effective [26]. Nonetheless, our nonadherence rate was lower than the rates found in large health plan studies (15\% vs. 27\%-45\%) [20, 29], which indicates a bias which might have weakened the external validity of this study. By means of a subjective measure to assess adherence, we obviously cannot exclude a reporting bias. However, a single-item, self-report adherence measure has been found to be associated with estrogen serum levels [7]. Also, we assessed necessity-concern beliefs at 3 months, whereas side-effect and coping expectations were assessed at treatment start. Since expectations might be affected by treatment experiences, comparability of these factors' trajectories may be limited. Finally, the numbers of nonadherers who were included in stability analyses $(n=8)$ and the numbers of patients who have specified the reason for discontinuation were very small $(n=9)$. Thus, interpretations must be viewed in light of limited representativeness.

\section{Conclusions}

In the context of the present body of research, our findings show a coherent picture indicating the importance of patients' understanding of the individual necessity of AET. More specifically, it seems important that necessity beliefs outweigh individual concerns, which are an inherent part of patients' treatment evaluations. Overall, patients reporting more necessity beliefs than concerns and experiencing fewer initial side effects were more likely to be adherent in the long term. Also, positive coping expectations with side effects of the AET decreased over time in nonadherent compared with adherent patients.

To reduce the perceived burden of side effects, practitioners could support patients' side-effect management [47]. Follow-up visitations could be used to screen patients with poor coping expectations, who are then provided with individual management strategies. In summary, by addressing benefits of the AET, by exploring potential concerns of a patient, and by offering coping strategies during the course of the treatment, adherence might be optimized in the long term.

Acknowledgements This study was conducted in association with the German Research Foundation, research unit FOR 1328 "Expectation and conditioning as basic processes of the placebo and nocebo response: From neurobiology to clinical applications" (http://www. placeboforschung.de). The authors thank Ramona Loebke for calling patients and collecting follow-up data.

Funding This work was supported by a grant from the German Research Foundation (NE1635) to Prof. Nestoriuc, and by the university funds from the Philipps-University of Marburg.

\section{Compliance with ethical standards}

Conflict of interest W Rief received honoraria for talks and recommendations on placebo mechanisms from Bayer, Berlin Chemie, Heel. Further authors declare that they have no conflict of interest. 
Ethical approval This work was approved by the ethics committee for medical studies of the University of Marburg. It was conducted in compliance with the current laws of Germany. All procedures performed in studies involving human participants were in accordance with the ethical standards of the institutional and/or national research committee and with the 1964 Helsinki Declaration and its later amendments or comparable ethical standards.

Open Access This article is distributed under the terms of the Creative Commons Attribution 4.0 International License (http://creativecomm ons.org/licenses/by/4.0/), which permits unrestricted use, distribution, and reproduction in any medium, provided you give appropriate credit to the original author(s) and the source, provide a link to the Creative Commons license, and indicate if changes were made.

\section{References}

1. Aaronson NK, Ahmedzai S, Bergman B, Bullinger M, Cull A, Duez NJ, Filiberti A, Flechtner H, Fleishman SB, de Haes JC et al (1993) The European organization for research and treatment of cancer QLQ-C30: a quality-of-life instrument for use in international clinical trials in oncology. J Natl Cancer Inst 85:365-376

2. Aiello Bowles EJ, Boudreau DM, Chubak J, Yu O, Fujii M, Chestnut J, Buist DS (2012) Patient-reported discontinuation of endocrine therapy and related adverse effects among women with early-stage breast cancer. J Oncol Pract 8:e149-e157. https://doi. org/10.1200/JOP.2012.000543

3. Arem H, Sorkin M, Cartmel B, Fiellin M, Capozza S, Harrigan M, Ercolano E, Zhou Y, Sanft T, Gross C, Schmitz K, Neogi T, Hershman D, Ligibel J, Irwin ML (2016) Exercise adherence in a randomized trial of exercise on aromatase inhibitor arthralgias in breast cancer survivors: the hormones and physical exercise (HOPE) study. J Cancer Surviv 10:654-662. https://doi. org/10.1007/s11764-015-0511-6

4. Banning $M(2012)$ Adherence to adjuvant therapy in post-menopausal breast cancer patients: a review. Eur J Cancer Care 21:10 19. https://doi.org/10.1111/j.1365-2354.2011.01295.x

5. Bosco-Levy P, Jove J, Robinson P, Moore N, Fourrier-Reglat A, Bezin J (2016) Persistence to 5-year hormonal breast cancer therapy: a French national population-based study. Br J Cancer 115:912-919. https://doi.org/10.1038/bjc.2016.276

6. Brennan C, Worrall-Davies A, McMillan D, Gilbody S, House A (2010) The hospital anxiety and depression scale: a diagnostic meta-analysis of case-finding ability. J Psychosom Res 69:371378. https://doi.org/10.1016/j.jpsychores.2010.04.006

7. Brier MJ, Chambless D, Gross R, Su HI, DeMichele A, Mao JJ (2015) Association between self-report adherence measures and oestrogen suppression among breast cancer survivors on aromatase inhibitors. Eur J Cancer 51:1890-1896. https://doi. org/10.1016/j.ejca.2015.06.113

8. Bright EE, Petrie KJ, Partridge AH, Stanton AL (2016) Barriers to and facilitative processes of endocrine therapy adherence among women with breast cancer. Breast Cancer Res Treat 158:243-251. https://doi.org/10.1007/s10549-016-3871-3

9. Cahir C, Guinan E, Dombrowski SU, Sharp L, Bennett K (2015) Identifying the determinants of adjuvant hormonal therapy medication taking behaviour in women with stages I-III breast cancer: a systematic review and meta-analysis. Patient Educ Couns 98:1524-1539. https://doi.org/10.1016/j.pec.2015.05.013

10. Chilcot J, Norton S, Hunter MS (2014) Cognitive behaviour therapy for menopausal symptoms following breast cancer treatment: who benefits and how does it work? Maturitas 78:56-61. https:// doi.org/10.1016/j.maturitas.2014.01.007

11. Coates AS, Keshaviah A, Thurlimann B, Mouridsen H, Mauriac L, Forbes JF, Paridaens R, Castiglione-Gertsch M, Gelber RD, Colleoni M, Lang I, Del Mastro L, Smith I, Chirgwin J, Nogaret JM, Pienkowski T, Wardley A, Jakobsen EH, Price KN, Goldhirsch A (2007) Five years of letrozole compared with tamoxifen as initial adjuvant therapy for postmenopausal women with endocrine-responsive early breast cancer: update of study BIG 1-98. J Clin Oncol 25:486-492. https://doi.org/10.1200/ JCO.2006.08.8617

12. Colagiuri B, Zachariae R (2010) Patient expectancy and postchemotherapy nausea: a meta-analysis. Ann Behav Med 40:314. https://doi.org/10.1007/s12160-010-9186-4

13. Coleman RE, Bolten WW, Lansdown M, Dale S, Jackisch C, Merkel D, Maass N, Hadji P (2008) Aromatase inhibitorinduced arthralgia: clinical experience and treatment recommendations. Cancer Treat Rev 34:275. https://doi.org/10.1016 /j.ctrv.2007.10.004

14. Colloca L, Miller FG (2011) The nocebo effect and its relevance for clinical practice. Psychosom Med 73:598-603. https://doi. org/10.1097/PSY.0b013e3182294a50

15. Coombes RC, Kilburn LS, Snowdon CF, Paridaens R, Coleman RE, Jones SE, Jassem J, Van de Velde CJ, Delozier T, Alvarez I, Del Mastro L, Ortmann O, Diedrich K, Coates AS, Bajetta E, Holmberg SB, Dodwell D, Mickiewicz E, Andersen J, Lonning PE, Cocconi G, Forbes J, Castiglione M, Stuart N, Stewart A, Fallowfield LJ, Bertelli G, Hall E, Bogle RG, Carpentieri M, Colajori E, Subar M, Ireland E, Bliss JM, Intergroup Exemestane S (2007) Survival and safety of exemestane versus tamoxifen after 2-3 years tamoxifen treatment (intergroup exemestane study): a randomised controlled trial. Lancet 369:559-570. http s://doi.org/10.1016/S0140-6736(07)60200-1

16. Davies C, Pan H, Godwin J, Gray R, Arriagada R, Raina V, Abraham M, Alencar VHM, Badran A, Bonfill X, Bradbury J, Clarke M, Collins R, Davis SR, Delmestri A, Forbes JF, Haddad P, Hou M-F, Inbar M, Khaled H, Kielanowska J, Kwan W-H, Mathew BS, Mittra I, Müller B, Nicolucci A, Peralta O, Pernas F, Petruzelka L, Pienkowski T, Radhika R, Rajan B, Rubach MT, Tort S, Urrútia G, Valentini M, Wang Y, Peto R (2013) Long-term effects of continuing adjuvant tamoxifen to 10 years versus stopping at 5 years after diagnosis of oestrogen receptor-positive breast cancer: ATLAS, a randomised trial. Lancet 381:805-816. https://doi.org/10.1016/s0140-6736(12)61963-1

17. Dent SF, Gaspo R, Kissner M, Pritchard KI (2011) Aromatase inhibitor therapy: toxicities and management strategies in the treatment of postmenopausal women with hormone-sensitive early breast cancer. Breast Cancer Res Treat 126:295-310. http s://doi.org/10.1007/s10549-011-1351-3

18. Fink AK, Gurwitz J, Rakowski W, Guadagnoli E, Silliman RA (2004) Patient beliefs and tamoxifen discontinuance in older women with estrogen receptor-positive breast cancer. J Clin Oncol 22:3309-3315. https://doi.org/10.1200/JCO.2004.11.064

19. Grunfeld EA, Hunter MS, Sikka P, Mittal S (2005) Adherence beliefs among breast cancer patients taking tamoxifen. Patient Educ Couns 59:97-102. https://doi.org/10.1016/j.pec.2004 .10 .005

20. Hadji P (2010) Improving compliance and persistence to adjuvant tamoxifen and aromatase inhibitor therapy. Crit Rev Oncol Hematol 73:156-166. https://doi.org/10.1016/j.critrevonc.2009.02.001

21. Hadji P, Blettner M, Harbeck N, Jackisch C, Luck HJ, WindemuthKieselbach C, Zaun S, Kreienberg R (2013) The patient's anastrozole compliance to therapy (PACT) Program: a randomized, in-practice study on the impact of a standardized information program on persistence and compliance to adjuvant endocrine 
therapy in postmenopausal women with early breast cancer. Ann Oncol 24:1505-1512. https://doi.org/10.1093/annonc/mds653

22. Heisig SR, Shedden-Mora MC, von Blanckenburg P, Schuricht F, Rief W, Albert US, Nestoriuc Y (2015) Informing women with breast cancer about endocrine therapy: effects on knowledge and adherence. Psychooncology 24:130-137. https://doi.org/10.1002 /pon.3611

23. Horne R, Chapman SC, Parham R, Freemantle N, Forbes A, Cooper V (2013) Understanding patients' adherence-related beliefs about medicines prescribed for long-term conditions: a meta-analytic review of the necessity-concerns framework. PLoS ONE 8:e80633. https://doi.org/10.1371/journal.pone.0080 633

24. Horne R, Weinman J, Hankins M (1999) The beliefs about medicines questionnaire: the development and evaluation of a new method for assessing the cognitive representation of medication. Psychol Health 14:1-24. https://doi.org/10.1080/088704499084 07311

25. Huiart L, Ferdynus C, Giorgi R (2013) A meta-regression analysis of the available data on adherence to adjuvant hormonal therapy in breast cancer: summarizing the data for clinicians. Breast Cancer Res Treat 138:325-328. https://doi.org/10.1007 /s 10549-013-2422-4

26. Hurtado-de-Mendoza A, Cabling ML, Lobo T, Dash C, Sheppard VB (2016) Behavioral interventions to enhance adherence to hormone therapy in breast cancer survivors: a systematic literature review. Clin Breast Cancer 16(247-255):e243. http s://doi.org/10.1016/j.clbc.2016.03.006

27. International Agency for Research on Cancer (2014) World cancer report 2014. WHO, Lyon

28. Jacob Arriola KR, Mason TA, Bannon KA, Holmes C, Powell CL, Horne K, O'Regan R (2014) Modifiable risk factors for adherence to adjuvant endocrine therapy among breast cancer patients. Patient Educ Couns 95:98-103. https://doi.org/10.1016 /j.pec.2013.12.019

29. Kemp A, Preen DB, Saunders C, Boyle F, Bulsara M, Malacova E, Roughead EE (2014) Early discontinuation of endocrine therapy for breast cancer: who is at risk in clinical practice? Springerplus 3:282. https://doi.org/10.1186/2193-1801-3-282

30. Lash TL, Fox MP, Westrup JL, Fink AK, Silliman RA (2006) Adherence to tamoxifen over the 5-year course. Breast Cancer Res Treat 99:215-220. https://doi.org/10.1007/s10549-0069193-0

31. Mausbach BT, Schwab RB, Irwin SA (2015) Depression as a predictor of adherence to adjuvant endocrine therapy (AET) in women with breast cancer: a systematic review and metaanalysis. Breast Cancer Res Treat 152:239-246. https://doi. org/10.1007/s10549-015-3471-7

32. McCowan C, Shearer J, Donnan PT, Dewar JA, Crilly M, Thompson AM, Fahey TP (2008) Cohort study examining tamoxifen adherence and its relationship to mortality in women with breast cancer. Br J Cancer 99:1763-1768. https://doi. org/10.1038/sj.bjc.6604758

33. McCowan C, Wang S, Thompson AM, Makubate B, Petrie DJ (2013) The value of high adherence to tamoxifen in women with breast cancer: a community-based cohort study. Br J Cancer 109:1172-1180. https://doi.org/10.1038/bjc.2013.464

34. Moon Z, Moss-Morris R, Hunter MS, Carlisle S, Hughes LD (2017) Barriers and facilitators of adjuvant hormone therapy adherence and persistence in women with breast cancer: a systematic review. Patient Prefer Adherence 11:305-322. https:// doi.org/10.2147/PPA.S126651

35. Moon Z, Moss-Morris R, Hunter MS, Hughes LD (2017) Understanding tamoxifen adherence in women with breast cancer: a qualitative study. Br J Health Psychol 22:978-997. https://doi. org/10.1111/bjhp.12266
36. Murphy CC, Bartholomew LK, Carpentier MY, Bluethmann SM, Vernon SW (2012) Adherence to adjuvant hormonal therapy among breast cancer survivors in clinical practice: a systematic review. Breast Cancer Res Treat 134:459-478. https:// doi.org/10.1007/s10549-012-2114-5

37. National Comprehensive Cancer Network (2016) NCCN clinical practice guidelines in oncology: breast cancer. Version 2:2016. https://doi.org/10.6004/jncen.2012.0046

38. Nestoriuc Y, von Blanckenburg P, Schuricht F, Barsky AJ, Hadji P, Albert US, Rief W (2016) Is it best to expect the worst? Influence of patients' side-effect expectations on endocrine treatment outcome in a 2-year prospective clinical cohort study. Ann Oncol 27:1909-1915. https://doi.org/10.1093/annonc/mdw266

39. Rief W, Glombiewski JA, Barsky AJ (2009) Generic Assessment of Side Effects: GASE. In:Verlag Hans Huber, Bern

40. Schafer JL (1997) Analysis of Incomplete Multivariate Data. Chapman \& Hall, London

41. Sohl SJ, Schnur JB, Montgomery GH (2009) A meta-analysis of the relationship between response expectancies and cancer treatment-related side effects. J Pain Symptom Manage 38:775784. https://doi.org/10.1016/j.jpainsymman.2009.01.008

42. Stanton AL, Petrie KJ, Partridge AH (2014) Contributors to nonadherence and nonpersistence with endocrine therapy in breast cancer survivors recruited from an online research registry. Breast Cancer Res Treat 145:525-534. https://doi. org/10.1007/s10549-014-2961-3

43. The Atac Trialists' Group, Forbes JF, Cuzick J, Buzdar A, Howell A, Tobias JS, Baum M (2008) Effect of anastrozole and tamoxifen as adjuvant treatment for early-stage breast cancer: 100-month analysis of the ATAC trial. Lancet Oncol 9:45-53. https://doi.org/10.1016/S1470-2045(07)70385-6

44. The North American Menopause Society (2015) Nonhormonal management of menopause-associated vasomotor symptoms: 2015 position statement of The North American Menopause Society. Menopause 22:1155-1172. https://doi.org/10.1097/ GME.0000000000000546

45. Van Liew JR, Christensen AJ, de Moor JS (2014) Psychosocial factors in adjuvant hormone therapy for breast cancer: an emerging context for adherence research. J Cancer Surviv 8:521-531. https://doi.org/10.1007/s11764-014-0374-2

46. Verbrugghe M, Verhaeghe S, Decoene E, De Baere S, Vandendorpe B, Van Hecke A (2017) Factors influencing the process of medication (non-)adherence and (non-)persistence in breast cancer patients with adjuvant antihormonal therapy: a qualitative study. Eur J Cancer Care 26:n/a-n/a. https://doi.org/10.1111 lecc.12339

47. von Blanckenburg P, Schuricht F, Albert US, Rief W, Nestoriuc Y (2013) Optimizing expectations to prevent side effects and enhance quality of life in breast cancer patients undergoing endocrine therapy: study protocol of a randomized controlled trial. BMC Cancer 13:426. https://doi.org/10.1186/1471-2407 $-13-426$

48. Wells KJ, Pan TM, Vazquez-Otero C, Ung D, Ustjanauskas AE, Munoz D, Laronga C, Roetzheim RG, Goldenstein M, Carrizosa C, Nuhaily S, Johnson K, Norton M, Sims E, Quinn GP (2016) Barriers and facilitators to endocrine therapy adherence among underserved hormone-receptor-positive breast cancer survivors: a qualitative study. Support Care Cancer 24:4123-4130. https:// doi.org/10.1007/s00520-016-3229-8

49. Wheeler SB, Roberts MC, Bloom D, Reeder-Hayes KE, Espada M, Peppercorn J, Golin CE, Earp JA (2016) Oncology providers' perspectives on endocrine therapy prescribing and management. Patient Prefer Adher 10:2007-2019. https://doi. org/10.2147/PPA.S95594

50. Wigertz A, Ahlgren J, Holmqvist M, Fornander T, Adolfsson J, Lindman H, Bergkvist L, Lambe M (2012) Adherence and 
discontinuation of adjuvant hormonal therapy in breast cancer patients: a population-based study. Breast Cancer Res Treat 133:367-373. https://doi.org/10.1007/s10549-012-1961-4

51. Wing JK, Babor T, Brugha T, Burke J, Cooper JE, Giel R, Jablenski A, Regier D, Sartorius N (1990) SCAN schedules for clinical assessment in neuropsychiatry. Arch Gen Psychiatry 47:589-593

52. Wouters H, van Geffen EC, Baas-Thijssen MC, Krol-Warmerdam EM, Stiggelbout AM, Belitser S, Bouvy ML, van Dijk L (2013) Disentangling breast cancer patients' perceptions and experiences with regard to endocrine therapy: nature and relevance for non-adherence. Breast 22:661-666. https://doi. org/10.1016/j.breast.2013.05.005

53. Zigmond AS, Snaith RP (1983) The hospital anxiety and depression scale. Acta Psychiatr Scand 67:361-370. https://doi. org/10.1111/j.1600-0447.1983.tb09716.x

54. Ziller V, Kalder M, Albert US, Holzhauer W, Ziller M, Wagner U, Hadji P (2009) Adherence to adjuvant endocrine therapy in postmenopausal women with breast cancer. Ann Oncol 20:431-436. https://doi.org/10.1093/annonc/mdn646 